\title{
Olive oil and haemostasis: a review on its healthy effects
}

\author{
Francisco Pérez-Jiménez* , Javier Delgado Lista, Pablo Pérez-Martínez, \\ Fernando López-Segura, Francisco Fuentes, Begoña Cortés, Aquiles Lozano \\ and José López-Miranda \\ Lipids and Atherosclerosis Unit, Reina Sofía University Hospital, University of Cordoba, Spain
}

\section{Submitted 1 June 2006: Accepted 14 November 2006}

\begin{abstract}
Interest in the Mediterranean diet (MD) has grown worldwide. Despite the high complexity of its nutrients composition, olive oil emerges as its principal food, since it provides the higher percentage of energy and a lot of bioactive compounds.

Objective: In this review, we will discuss the benefits of diets enriched in virgin olive oil, whose effects are probably due not only to its oleic acid content but also to its other potentially health-promoting components.

Methods: Traditionally, the benefits of MD were linked to its effect on lipoprotein metabolism, but today we realise that there exists a whole sheaf of other benefits, including the components of haemostasis: platelet function, thrombogenesis and fibrinolysis.

Results: A diet enriched in virgin olive oil can reduce the sensitivity of platelets to aggregation, decreasing von Willebrand and thromboxane $\mathrm{B}_{2}$ plasma levels. Moreover, a particular interest has aroused about its capacity to decrease fasting factor VII plasma levels and to avoid or modulate its postprandial activation. In addition, tissue factor expression in mononuclear cells could be reduced with the chronic intake of virgin olive oil, and finally, studies performed in different experimental situation have shown that it could also increase fibrinolytic activity, reducing plasma concentration of plasma activator inhibitor type-1 (PAI-1).

Conclusion: The MD is an alimentary model with a high content of monounsaturated fats that is capable of inducing a wide range of biological effects on the cardiovascular system. The application of modern focuses of study will dilucidate in the future the biological and clinical interest of these findings.
\end{abstract}

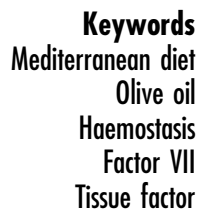

\section{Introduction}

Interest in the Mediterranean diet (MD) has grown worldwide in the course of the past decade, even among nutritionists outside of the Mediterranean area. This is largely due to the fact that the consumption of the MD has been linked to greater longevity, improved quality of life and lower incidences of cardiovascular disease, cancer and age cognitive decline, in spite of being a dietary model with a high fat content, unlike the diets recommended for several decades by many experts in nutrition in other geographical areas ${ }^{1}$. However, most of the fat content of the MD is derived from a single component of the diet, namely olive oil, which means that the diet is low in saturated fats and high in monounsaturated fatty acids (MUFA), particularly in oleic acid. Moreover, the gastronomic characteristics of this dietary component encourage a higher level of consumption of plant products such as fruit, vegetables, pulses and cereals, all of which are foods that contain a high proportion of low glycaemic index carbohydrates and that have important potential for promoting good health ${ }^{2}$. In the course of the past few years, thanks to modern technology, other types of oil with similar fat composition have become available to human nutrition. These include oils obtained from certain types of seed, some of whose varieties are high in oleic acid, such as high oleic sunflower, soya and rapeseed oils. This situation has generated a new concept of MD, according to which dietary oleic acid is not necessarily derived predominantly from olive oil but rather from seeds ${ }^{3,4}$. However, unlike virgin olive oil, these must be refined to be intake, as a result they do not contain the non-fat microcomponents, present in virgin olive oil, much of them with a high biological potency, including the phenols (tyrosol and hydroxytyrosol), secoroids (oleuropein and its conjugate forms) and lignans ${ }^{5}$. This is important, because in this study we will discuss the benefits of diets rich in virgin olive oil, the genuine MD, whose effects are due not only to its oleic acid content but also to its other potentially health-promoting components.

Traditionally, the benefits of MUFA-rich diets were linked to its effect on lipoprotein metabolism and, to a 
lesser extent, to other risk factors, but today we realise that there exists a whole sheaf of other benefits, including the components of haemostasis ${ }^{6-12}$. The interest that this has aroused in the course of the past few years is perfectly understandable when we take into account that, in persons at high risk of cardiovascular disease, there may well be present a chronic activation of the mechanisms of thrombosis, resulting in what might be called a prothrombotic environment ${ }^{10}$. Thrombogenesis is a very complex process, which involves the platelets activation (primary haemostasis), the mechanisms of coagulation (secondary haemostasis) and fibrinolysis, a system that has been implicated in the reabsorption of recently formed fibrin thrombus (Fig. 1). However, all these mechanisms are capable of being modulated by olive oil, as it is summarised in Table 1.

\section{Platelet function}

Some years ago, Sirtori et al. observed that in healthy persons, a diet rich in olive oil lowered the sensitivity of platelets to collagen-induced aggregation, while if the diet was enriched with corn oil, the threshold of aggregation to arachidonic acid was also raised ${ }^{13}$. It was subsequently confirmed that in comparison with another diet with an elevated content of polyunsaturates, a MUFArich diet diminished the urinary excretion of 11-dehydrothromboxane $\mathrm{B}_{2}$, a metabolite of thromboxane $\mathrm{B}_{2}\left(\mathrm{TXB}_{2}\right)$, which in turn is derived from $\mathrm{TXA}_{2}$, a product that encourages aggregation, generated by the action of the cyclooxygenase found in platelets and the endothelium ${ }^{14}$. More recent studies of the functions of the platelets have produced varying results, even to the extent of suggesting that the ingestion of MUFA induces unfavourable actions that resemble those of saturated fatty acids, with an increase in the urinary excretion of $\mathrm{TXB}_{2}$ metabolites $^{15-17}$. There are many potential explanations for the existence of such wide range of results, which is otherwise a fairly normal situation in intervention studies, given their great complexity and the special difficulties associated with studies carried out on human beings, who are so heterogeneous in their design and with features peculiar to different populations. We also need to take into account the methodological and experimental differences between individual studies, including the potential confusion that results from the wide range of foods and nutritional factors involved, whose ingestion may well be modified when we design a study in which the total content and the proportion of dietary fats are altered $^{18}$. At any rate, recent studies appear to confirm the initial results, which noted the beneficial effects of MUFArich diets on platelets. In one such study, 8 weeks of a diet high in rapeseed and sunflower oils, both of which have a high oleic acid content, reduced the aggregation to three agonists (arachidonic acid, collagen and ADP), although by the end of 16 weeks only the effect on the last-named of these was maintained ${ }^{19}$. The same authors confirmed these data in a carefully designed study of two levels of ingestion of MUFA (18 and 15\% of the total supply of calories) by comparing this dietary component with saturated fats (16\%). Although the effect of the elevated consumption was greater in the short term (8 weeks), the results were identical after 16 weeks at both levels of ingestion, maintaining the lower level of aggregation induced by arachidonic $\operatorname{acid}^{20}$. Another

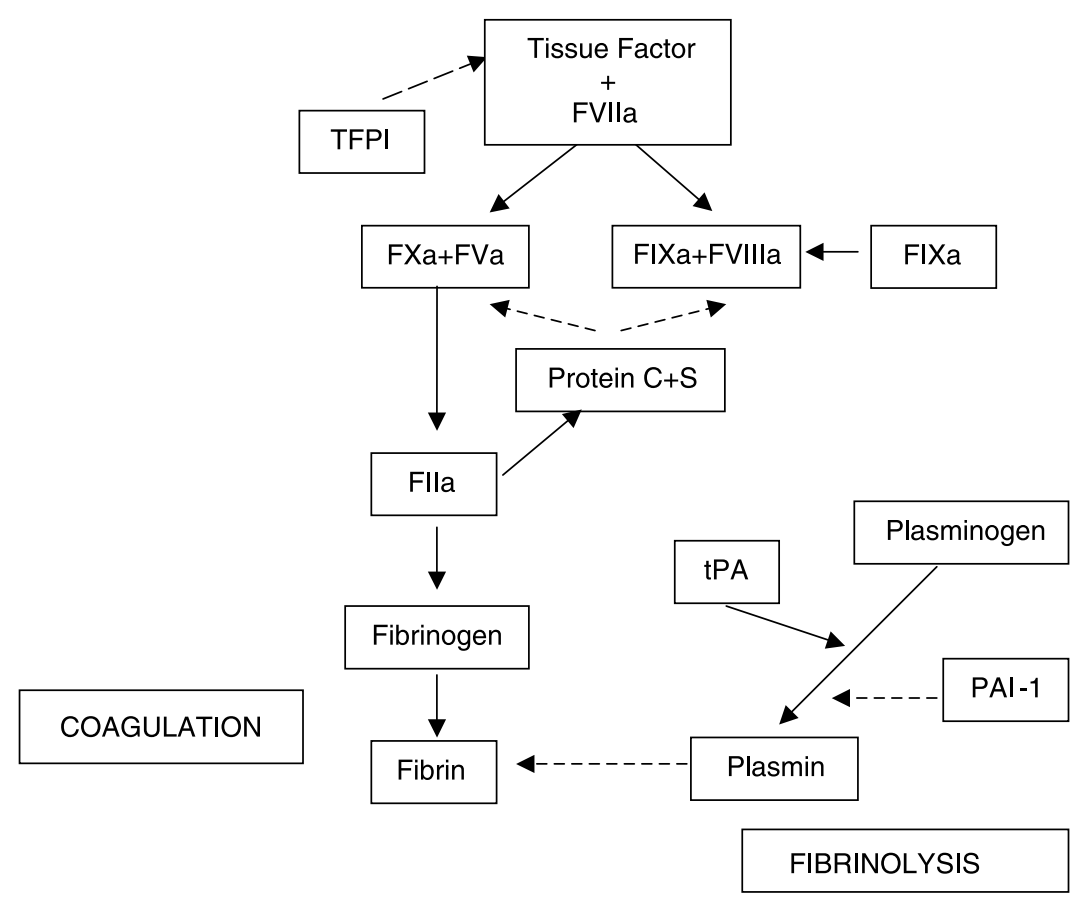

Fig. 1 Coagulation and fibrinolysis cascade. Continuous lines represent stimulation. Discontinuous lines represent inhibition 
Table 1 Haemostatic effects favoured by the intake of virgin olive oil-enriched diet

\begin{tabular}{ll}
\hline $\begin{array}{l}\text { Platelet aggregation } \\
\text { Thromboxane B2 }\end{array}$ & $\begin{array}{l}\text { Reduced comparing with saturated fat } \\
\text { Lower plasma levels in fasting and } \\
\text { postprandial state } \\
\text { Von Willebrand factor } \\
\text { healthy people }\end{array}$ \\
Tissue factor & $\begin{array}{l}\text { Reduced expression in mononuclear cells } \\
\text { compared with saturated fat } \\
\text { Decrease compared with SAFA }\end{array}$ \\
TFPI & $\begin{array}{l}\text { Reduction in plasma levels compared } \\
\text { high saturated fat-enriched diets } \\
\text { Reduction in plasma fasting levels and } \\
\text { lower postprandial activation } \\
\text { Decrease compared with saturated fat }\end{array}$ \\
Factor VII &
\end{tabular}

interesting question concerns whether the richness in minor components of the oils utilised in these studies might be capable of having a specific influence on primary haemostasis. With this idea in mind, Visoli et al. observed that daily administration of $40 \mathrm{ml}$ of virgin olive oil rich in phenolic compounds, compared with refined oil, was accompanied after 7 weeks by a lower TXB2 plasma levels content ${ }^{21}$. More recently, the same authors have confirmed these findings, in this case through experiments carried out during the postprandial phase of the ingestion of oils similar to those used in the previous study $^{22}$. This recalls perfectly the in vitro data in experiments on endothelial cells from the umbilical cord, which secreted less TXB2 when they were exposed to postprandial particles obtained after the consumption of olive oil enriched with micronutrients, although this experiments did not identify with any degree of certainty just which components this effect could be attributed to $^{23}$. Finally, one component of the circulation in haemostasis, which favours the adherence of the platelets to the disrupted endothelium, i.e. the von Willebrand factor (vWF), may be decreased by diets rich in olive oil, although the biological significance of these facts is not well known ${ }^{24}$.

\section{Coagulation patbway}

One of the components of haemostasis that has aroused particular interest is factor VII (FVII), since it may play a central role in the development of coronary disease ${ }^{25,26}$. The first studies confirmed that the activity of fasting FVII plasma levels are increased with the regular ingestion of any type of fat, with the result that palmitic acid would raise the levels of the coagulant fraction (FVIIc) ${ }^{27}$, while MUFA would elevate activated FVII (FVIIa) ${ }^{28}$. A study performed using oleic acid observed a possible sexlinked effect, in that only female subjects displayed decreased levels while they were consuming fatty acidrich diets, compared with those containing saturated fats $^{29}$. This favourable effect has also been confirmed with the ingestion of MUFA derived from rapeseed oil by hypertriglyceridaemic patients ${ }^{30}$, as well as in another population in which an olive oil-rich MD model was compared with two others, one of which was rich in carbohydrates while the other contained a high proportion of saturated fats ${ }^{31}$. It should be emphasised that in this case, FVII levels fell only with the MD. The possibility that MUFA has a special effect on FVIIc is reinforced by the fact that its level in the plasma of healthy person is reduced with a sunflower oil-rich diet that is high in oleics ${ }^{32}$. Similarly, Larsen et al. did not observe any differences in either FVIIa or FVIIc in a comparison of various high-MUFA oils pressed from seeds (sunflower, olive and rapeseed), although in one postprandial study the increase in FVIIa was less following ingestion of virgin olive oil, suggesting that its micronutrients might modulate the fat-induced activation of FVII. An interesting fact that has recently emerged is that postprandial activation of FVII, following the acute ingestion of fat, may depend on the background diet prior to the acute ingestion phase, so that chronic consumption of olive oil would prevent the acute activation of FVII $^{33}$. Similar results have been observed during a prolonged MUFA-rich diet (18\% of the total energy provided by MUFA) compared with another diet with 15\% from MUFA, derived from refined oils. This finding, confirmed by other authors, might be explained why the consumption of a background diet, enriched in MUFA, could lower the number of postprandial chylomicrons during the acute fat overload phase, reducing the activation of $\mathrm{FVII}^{34}$.

Tissue factor (TF) is expressed in the arterial wall cells and its presence increases coagulatory activity in atheroma plaques, encouraging the emergence of acute coronary syndrome. The quantity and quality of fatty acids in the diet regulate its expression. We already know that the ingestion of polyunsaturated fatty acids inhibits the stimulating effect of lipopolysaccharides in mononuclear cells, while saturated fats raise postprandial levels and diets that are low in fat and the MD reduces its level of activity in mononuclear cells ${ }^{35-37}$. Tissue factor pathway inhibitor (TFPI) is an activated factor Xdependent inhibitor of TF-induced coagulation. The principal role of TFPI appears to be to inhibit the activity of small amounts of TF, which are probably essential for the maintenance of normal haemostatic balance. It has been shown that TFPI in the plasma of crab-eating macaques rises markedly in response to a highcholesterol $\operatorname{diet}^{38}$. Furthermore, we have shown that the isocaloric replacement of a palm oil-enriched diet or a low-fat diet by a MD had the effect of reducing plasma TFPI. Although the decrease in TFPI levels is difficult to interpret, it has been suggested that it may reflect an increased presence of the protease in the endothelium, which would have a regulatory effect on thrombogenesis. In this way, the decrease in plasma TFPI levels would therefore be interpreted as protective effect against thrombogenesis ${ }^{39}$. 
Data concerning fibrinogen are less definite, possibly because the fact that it is a marker of inflammation means that changes may depend principally on the underlying inflammation rather than on a specific effect of nutrients. In a study in which subjects consumed a diet rich in MUFA derived from refined oils, plasma levels of fibrinogen rose, while a MD reduced them in parallel with other parameters of inflammation ${ }^{40}$. More studies are needed in order to clarify these effects ${ }^{41}$.

\section{Fibrinolysis patbway}

This key mechanism is fundamental to the maintenance of adequate haemostatic equilibrium, since it avoids thrombogenesis on blood vessel walls. Its fibrinolytic action depends on the action of tissue plasminogen activator (tPA), an enzyme that favours the production of plasmin, which hydrolyses recently created fibrin, thus hindering the growth of the thrombus. Its most important mechanism of regulation depends on the equilibrium in the plasma between TPA and PAI-1 (tPA inhibitor type 1), and it is known that the level of the latter substance rises with the ingestion of diets that are high in palmitic acid ${ }^{42}$. A study performed by our group has already demonstrated that a MD, rich in olive oil, reduced levels of PAI-1 in comparison with another carbohydrate-rich, low-fat diet, independently of the dietary cholesterol content in the diet $^{43}$. However, there exist data that disagree with these findings, as have been provided by a study carried out using refined high oleic seed oils, which found no changes in PAI-1 levels. However, more recently, the use of a diet rich in virgin olive oil in hypertensive patients confirmed our previous data, reducing PAI-1 plasma concentration in comparison with soya oil ${ }^{44}$. Other subsequent studies using diets rich in virgin olive oil have reconfirmed its beneficial effects, leading us to speculate that its micronutrients may have a specific action, so that the possible reduction in PAI-1 may be dependent on such components rather than on its content of oleic acid ${ }^{39,45}$.

\section{Relationship between thrombosis and the endotbelium}

The initial alteration that precedes the development of arteriosclerosis is the activation of the endothelium, through which the cells that line the vessel walls express, on the surface of their lumen, a combination of molecules that encourage the adhesion and migration of the circulating mononuclear cells to the sub-endothelial space. This forms the initiation of the inflammatory process, one of the consequences of which is the loss of endothelial functions. Among these functions are the wellknown vasodilatory response that is dependent on the production of nitric oxide, and its capacity to reduce thrombogenesis, which is the subject of this review. The cellular mechanism, which mediates the expression of the genes involved in the inflammatory response, both in the endothelium and in other cells that contribute to the inflammation of the vascular walls, depends on the cytoplasmic expression of the transcription factors. Among them, NF- $\mathrm{KB}$ is particularly interesting as the mediator sensitive to oxidative changes and as that which induces the activation of the genes that are involved in the synthesis of the adhesion molecules. Of special interest in this respect is the demonstration that oleic acid buffers the inflammatory process that leads to endothelial dysfunction $^{46-48}$. Although we now find ourselves in fairly speculative field, where we do not even know what initiates the initial phenomenon of wall lesions, the antiinflammatory effect of olive oil needs to be considered in the context of the interaction produced during the ingestion of high-energy diets that are capable of promoting the overproduction of reactive species of oxygen and inducing changes in fraction 3 of the complement ${ }^{49,50}$. Data that exist suggest that fats with antioxidative or membrane-stabilising capacity might be capable of protecting endothelial cells ${ }^{51}$. In this context, olive oil has such an ability, both through its high content of MUFA ${ }^{52-54}$ and via the antioxidative effect of its microcomponents, particularly of phenolic compounds, among which the typical is the oleuropein, an aglycone the hydrolysis of which generates tyrosol and hydroxytyrosol, which in their free, secoroid and conjugated forms make up some $80 \%$ of the phenolic compounds of virgin olive oil. These products are absorbed by the intestine in human beings, as has been demonstrated by experimental studies, possess antioxidative and antiinflammatory properties, and are also capable of modifying haemostasis, inhibiting platelet aggregation and displaying antithrombotic properties ${ }^{55}$.

In summary, the MD is an alimentary model with a high content of monounsaturated fats that is capable of inducing a wide range of biological effects on the cardiovascular system. Of these effects, haemostasis is of particular importance with regard to both thrombogenesis and fibrinolysis. These beneficial effects are united to their capacity to protect the endothelium, an ability that is linked with MUFA, their predominant type of fat species and to their elevated content of other components that display a wide range of biological activities. In the future, the application of modern focuses of study based on nutrigenetics will enable us to understand in greater depth this interesting biological effect, which will probably turn out to play a key role in the prevention of cardiovascular disease.

\section{Acknowledgements}

This work was supported by research grants from the Plan Andaluz de Investigación (Proyecto de Excelencia AGR 922; Consejería de Innovación Ciencia y Empresa de la Junta de Andalucía) and from the Plan Nacional de Investigación (Ministerio de Educación y Ciencia; SAF2003-05 770) to FPJ. 


\section{References}

1 Perez-Jimenez F. International conference on the healthy effect of virgin olive oil. European Journal of Clinical Investigation 2005; 35: 421-4.

2 Serra-Majem Ll, Cruz JN, Ribas L, Tur JA. Olive oil and the Mediterranean diet: beyond the rhetoric. European Journal of Clinical Nutrition 2003; 57: 2-7.

3 Singh RB, Dubnov G, Niaz MA, Ghosh S, Singh R, Rastogi SS, et al. Effect of an Indo-Mediterranean diet on progression of coronary artery disease in high risk patients (IndoMediterranean Diet Heart Study): a randomised singleblind trial. Lancet 2002; 360: 1455-61.

4 de Lorgeril M, Renaud S, Mamelle N, Salen P, Martin JL, Monjaud I, Guidollet J, Touboul P, Delaye J. Mediterranean alpha-linolenic acid-rich diet in secondary prevention of coronary heart disease. Lancet 1994; 343: 1454-9.

5 Owen RW, Giacosa A, Hull WE, Haubner R, Wurtele G, Spiegelhalder B, Bartsch $\mathrm{H}$. Olive-oil consumption and health: the possible role of antioxidants. Lancet Oncology 2000; 1: 107-12.

6 Keys A. Coronary heart disease in seven countries. Circulation 1970; 41: 1-211.

7 Mensink RP, Zock PL, Kester AD, Katan MB. Effects of dietary fatty acids and carbohydrates on the ratio of serum total to HDL cholesterol and on serum lipids and apolipoproteins: a meta-analysis of 60 controlled trials. The American Journal of Clinical Nutrition 2003; 77: 1146-55.

8 Pérez-Jiménez F, Fuentes F, Fernández de la Puebla R, López-Miranda J. Efectos pleiotrópicos de la grasa de la dieta sobre el riesgo cardiovascular. Clinica e investigacion en arteriosclerosis 2003; 15: 27-32.

9 Pérez-Jiménez F, López-Miranda J, Mata P. Protective effect of dietary monounsaturated fat on arteriosclerosis: beyond cholesterol. Atherosclerosis 2002; 163: 385-98.

10 Mutanen M, Freese R. Fats, lipids and blood coagulation. Current Opinion in Lipidology 2001; 12: 25-9.

11 Moreno JJ, Mitjavila MT. The degree of unsaturation of dietary fatty acids and the development of atherosclerosis. The Journal of Nutritional Biochemistry 2003; 14: 182-95.

12 Visioli F, Bogani P, Grande S, Galli C, Sirtori C. Mediterranean food and health: building human evidence. Journal of Physiology and Pharmacology 2005; 56: 37-49.

13 Sirtori CR, Tremoli E, Gatti E, Montanari G, Sirtori M, Colli S, Gianfranceschi G, Maderna P, Dentone CZ, Testolin G. Controlled evaluation of fat intake in the Mediterranean diet: comparative activities of olive oil and corn oil on plasma lipids and platelets in high-risk patients. The American Journal of Clinical Nutrition 1986; 44: 635-42.

14 Lahoz C, Alonso R, Ordovas JM, Lopez-Farre A, de Oya M, Mata P. Effects of dietary fat saturation on eicosanoid production, platelet aggregation and blood pressure. European Journal of Clinical Investigation 1997; 27: 780-7.

15 Thijssen MA, Hornstra G, Mensink RP. Stearic, oleic, and linoleic acids have comparable effects on markers of thrombotic tendency in healthy human subjects. Journal of Nutrition 2005; 135: 2805-11.

16 Freese R, Mutanen M, Valsta LM, Salminen I. Comparison of the effects of two diets rich in monounsaturated fatty acids differing in their linoleic/alpha-linolenic acid ratio on platelet aggregation. Thrombosis and Haemostasis 1994; 71: 73-7.

17 Turpeinen AM, Pajari AM, Freese R, Sauer R, Mutanen M. Replacement of dietary saturated by unsaturated fatty acids: effects of platelet protein kinase $\mathrm{C}$ activity, urinary content of 2,3-dinor-TXB2 and in vitro platelet aggregation in healthy man. Thrombosis and Haemostasis 1998; 80: 649-55.

18 Rajaram S. The effect of vegetarian diet, plant foods, and phytochemicals on hemostasis and thrombosis. The American Journal of Clinical Nutrition 2003; 78: 552-8.
19 Kelly CM, Smith RD, Williams CM. Dietary monounsaturated fatty acids and haemostasis. The Proceedings of the Nutrition Society 2001; 60: 161-70.

20 Smith RD, Kelly CN, Fielding BA, Hauton D, Silva KD, Nydahl MC, Miller GJ, Williams CM. Long-term monounsaturated fatty acid diets reduce platelet aggregation in healthy young subjects. The British Journal of Nutrition 2003; 90 : 597-606.

21 Visioli F, Caruso D, Grande S, Bosisio R, Villa M, Galli G, et al Virgin Olive Oil Study (VOLOS): vasoprotective potential of extra virgin olive oil in mildly dyslipidemic patients. European Journal of Nutrition 2005; 44: 121-7.

22 Bogani P, Galli C, Villa M, Visioli F. Postprandial antiinflammatory and antioxidant effects of extra virgin olive oil. Atherosclerosis 2007; 190: 167-73.

23 Perona JS, Martinez-Gonzalez J, Sanchez-Dominguez JM, Badimon L, Ruiz-Gutierrez V. The unsaponifiable fraction of virgin olive oil in chylomicrons from men improves the balance between vasoprotective and prothrombotic factors released by endothelial cells. Journal of Nutrition 2004; 134: 3284-9.

24 Rasmussen O, Thomsen C, Ingerslev J, Hermansen K. Decrease in von Willebrand factor levels after a highmonounsaturated-fat diet in non-insulin-dependent diabetic subjects. Metabolism 1994; 43: 1406-9.

25 Ye Z, Liu EH, Higgins JP, Keavney BD, Lowe GD, Collins R, Danesh J. Seven haemostatic gene polymorphism in coronary disease: meta-analysis of 66155 cases and 91307 controls. Lancet 2006; 367: 651-8.

26 Kohler HP, Grant PJ. Plasminogen-activator inhibitor type 1 and coronary artery disease. The New England Journal of Medicine 2000; 342: 1792-801.

27 Tholstrup T, Marckmann P, Jespersen J, Sandstrom B. Fat high in stearic acid favorably affects blood lipids and factor VII coagulant activity in comparison with fats high in palmitic acid or high in myristic and lauric acids. The American Journal of Clinical Nutrition 1994; 59: 371-7.

28 Sanders T, Grassi T, Millar G, Humphries S. Dietary oleic and palmitic acids and postprandial factor VII in middle-aged men heterozygous and homozygous for factor VII R353Q polymorphism. The American Journal of Clinical Nutrition 1999; 69: 220-5.

29 Temme EH, Mensink RP, Hornstra G. Effects of diets enriched in lauric, palmitic or oleic acids on blood coagulation and fibrinolysis. Thrombosis Haemostasis 1999; 81: $259-63$.

30 Junker R, Pieke B, Schulte H, Nofer R, Neufeld M, Assmann $\mathrm{G}$, Wahrburg U. Changes in hemostasis during treatment of hypertriglyceridemia with a diet rich in monounsaturated and $n-3$ polyunsaturated fatty acids in comparison with a low-fat diet. Thrombosis Research 2001; 101: 355-66.

31 Gomez P, Fernandez de la Puebla RA, Castro P, LopezMiranda J, Marin C, Fuentes F, Perez-Martinez P, Velasco F, Moreno JA, Torres A, Perez-Jimenez F. Effect of the Mediterranean diet on fasting concentrations of activated factor VII in healthy persons. Revista Espanola de Cardiologia 2005; 58: 285-9.

32 Turpeinen AM, Mutanen M. Similar effects of diet high in oleic or linoleic acids on coaugulation and fibrinolytic facdtors in helathy humans. Nutrition, Metabolism, and Cardiovascular Diseases 1999; 9: 65-72.

33 Roche HM, Zampelas A, Knapper JM, Webb D, Brooks C, Jackson KG, Wright JW, Gould BJ, Kafatos A, Gibney MJ, Williams CM. Effect of long-term olive oil dietary intervention on postprandial triacylglycerol and factor VII metabolism. The American Journal of Clinical Nutrition 1998; 68 : 552-60.

34 Silva KD, Kelly CN, Jones AE, Smith RD, Wootton SA, Miller GJ, Williams CM. Chylomicron particle size and number, 
factor VII activation and dietary monounsaturated fatty acids. Atherosclerosis 2003; 166: 73-84.

35 Tremoli E, Eligini S, Colli S, et al. $n$-3 fatty acid ethyl ester administration to healthy subjects and to hypertriglyceridemic patients reduces tissue factor activity in adherent monocytes. Arteriosclerosis Thrombosis 1994; 14: 1600-8.

36 Bravo-Herrera MD, Lopez-Miranda J, Marin C, Gomez P, Gomez MJ, Moreno JA, Perez-Martinez P, Blanco A, JimenezGomez Y, Perez-Jimenez F. Tissue factor expression is decreased in monocytes obtained from blood during Mediterranean or high carbohydrate diets. Nutrition, Metabolism, and Cardiovascular Diseases 2004; 14: 128-32.

37 Motton DD, Mackman N, Tilley RE, Rutledge JC. Postprandial elevation of tissue factor antigen in the blood of healthy adults. Thrombosis Haemostasis 2005; 94: 504-9.

38 Abumiya T, Nakamura S, Takenaka A, et al. Response of plasma tissue factor pathway inhibitor to diet-induced hypercholesterolemia in crab-eating monkeys. Arteriosclerosis Thrombosis 1994; 14: 483-8.

39 Perez-Jimenez F, Castro P, Lopez-Miranda J, Paz-Rojas E, Blanco A, Lopez-Segura F, Velasco F, Marin C, Fuentes F, Ordovas JM. Circulating levels of endothelial function are modulated by dietary monounsaturated fat. Atherosclerosis 1999; 145: 351-8.

40 Chrysohoou C, Panagiotakos DB, Pitsavos C, Das UN, Stefanadis C. Adherence to the Mediterranean diet attenuates inflammation and coagulation process in healthy adults: the ATTICA Study. Journal of the American College of Cardiology 2004; 44: 152-8.

41 Poppit SD. Postprandial lipaemia, haemostasis, inflammatory response and other emerging risk factors for cardiovascular disease: the influence of fatty meals. Current Nutrition and Food Sciences 2005; 1: 23-34.

42 Temme EH, Mensink RP, Hornstra G. Effects of diets enriched in lauric, palmitic or oleic acids on blood coagulation and fibrinolysis. Thrombosis Haemostasis 1999; 81: 259-63.

43 Lopez-Segura F, Velasco F, Lopez-Miranda J, Castro P, LopezPedrera R, Blanco A, Jimenez-Pereperez J, Torres A, Trujillo J, Ordovas JM, Perez-Jimenez F. Monounsaturated fatty acidenriched diet decreases plasma plasminogen activator inhibitor type 1. Arteriosclerosis Thrombosis and Vascular Biology 1996; 16: 82-8.

44 Trifiletti A, Scamardi R, Gaudio A, Lasco A, Frisina N. Hemostatic effects of diets containing olive or soy oil in hypertensive patients. Journal of Thrombosis and Haemostasis 2005; 3: 179-80.

45 Avellone G, Di Garbo V, Cordova R, Scaffidi L, Bompiani GD. Effects of Mediterranean diet on lipid, coagulative and fibrinolytic parameters in two randomly selected population samples in Western Sicily. Nutritional Metabolic Cardiovascular Diseases 1998; 8: 287-96.

46 Toborek M, Lee YW, Garrido R, Kaiser S, Hennig B. Unsaturated fatty acids selectively induce an inflammatory environment in human endothelial cells. The American Journal of Clinical Nutrition 2002; 75: 119-25.

47 Carluccio MA, Massaro M, Bonfrate C, Siculella L, Maffia M, Nicolardi G, Distante A, Storelli C, De Caterina R. Oleic acid inhibits endothelial activation: a direct vascular antiatherogenic mechanism of a nutritional component in the Mediterranean diet. Arteriosclerosis Thrombosis and Vascular Biology 1999; 19: 220-8.

48 Bellido C, Lopez-Miranda J, Blanco-Colio LM, PerezMartinez P, Muriana FJ, Martin-Ventura JL, Marin C, Gomez P, Fuentes F, Egido J, Perez-Jimenez F. Butter and walnuts, but not olive oil, elicit postprandial activation of nuclear transcription factor kappaB in peripheral blood mononuclear cells from healthy men. The American Journal of Clinical Nutrition 2004; 80: 1487-91.

49 Charo IF, Ransohoff RM. The many roles of chemokines and chemokine receptors in inflammation. The New England Journal of Medicine 2006; 354: 610-21.

50 van Oostrom AJ, Alipour A, Plokker TW, Sniderman AD, Cabezas MC. The metabolic syndrome in relation to complement component 3 and postprandial lipemia in patients from an outpatient lipid clinic and healthy volunteers. Atherosclerosis 2006 (In press).

51 Henning B, Toborek M, McClain CJ. High-energy diets, fatty acids and endothelial cell function: implications for atherosclerosis. Journal of the American College of Cardiology 2001; 20: 97-105.

52 Rodriguez-Villar C, Perez-Heras A, Mercade I, Casals E, Ros E. Comparison of a high-carbohydrate and a high-monounsaturated fat, olive oil-rich diet on the susceptibility of LDL to oxidative modification in subjects with Type 2 diabetes mellitus. Diabetic Medicine 2004; 21: 142-9.

53 Khan-Merchant N, Penumetcha M, Meilhac O, Parthasarathy $S$. Oxidized fatty acids promote atherosclerosis only in the presence of dietary cholesterol in low-density lipoprotein receptor knockout mice. Journal of Nutrition 2002; 132: 3256-62.

54 Mata P, Varela O, Alonso R, Lahoz C, de Oya M, Badimon L. Monounsaturated and polyunsaturated n-6 fatty acidenriched diets modify LDL oxidation and decrease human coronary smooth muscle cell DNA synthesis. Arteriosclerosis Thrombosis and Vascular Biology 1997; 17: 2088-95.

55 Owen RW, Mier W, Giacosa A, Hull WE, Spiegelhalder B, Bartsch $\mathrm{H}$. Phenolic compounds and squalene in olive oils: the concentration and antioxidant potential of total phenols, simple phenols, secoiridoids, lignansand squalene. Food and Chemical Toxicology 2000; 38: 647-59. 